\title{
Parametric Energy Simulation in Early Design: High-Rise Residential Buildings in Urban Contexts
}

\section{Citation}

Samuelson, Holly, Sebastian Claussnitzer, Apoorv Goyal, Yujiao Chen, and Alejandra RomoCastillo.2016. Parametric Energy Simulation in Early Design: High-Rise Residential Buildings in Urban Contexts. Building and Environment 101:19-31.

\section{Published Version}

10.1016/j.buildenv.2016.02.018

\section{Permanent link}

http://nrs.harvard.edu/urn-3:HUL.InstRepos:27754128

\section{Terms of Use}

This article was downloaded from Harvard University's DASH repository, and is made available under the terms and conditions applicable to Open Access Policy Articles, as set forth at http:// nrs.harvard.edu/urn-3:HUL.InstRepos:dash.current.terms-of-use\#OAP

\section{Share Your Story}

The Harvard community has made this article openly available.

Please share how this access benefits you. Submit a story.

\section{Accessibility}




\title{
Parametric Energy Simulation in Early Design: High-Rise Residential Buildings in Urban Contexts
}

\author{
Holly Samuelson $^{\mathrm{a}^{*}}$, Sebastian Claussnitzer, Apoorv Goyal ${ }^{\mathrm{a}}$, Yujiao Chen ${ }^{\mathrm{a}}$, \\ Alejandra Romo-Castillo ${ }^{a}$, \\ ${ }^{a}$ Harvard University \\ Graduate School of Design \\ 48 Quincy St. Cambridge, MA 02138 USA \\ *corresponding author: hsamuelson@gsd.harvard.edu
}

\section{ABSTRACT}

This paper presents a framework for the development of early-design guidance to inform architects and policy-makers using parametric whole-building energy simulation. It includes a case study of a prototype multifamily residential building, using an exhaustive search method and a total of 90,000+ simulations. The authors performed a simple sensitivity analysis to identify the most influential of the tested design parameters on energy use intensity, which included WWR, Glass Type, Building Rotation, Building Shape, and Wall Insulation, in that order. They identified synergies and trade-offs when designing for different energy objectives, including (a) decreasing Energy Use Intensity, (b) reducing peak-loads, and (c) increasing passive survivability - i.e., maintaining the safest interior temperatures in an extended power outage.

This paper also investigated the effect of urban context as a source of sun shading and found it to have a substantial impact on the design optimization. Ignoring urban context in energy simulation, a common practice, would mislead designers in some cases and result in sub-optimal design decisions. Since in generalized guidelines the future building site is unknown, the authors tested a method for generating urban contexts based on the floor area ratio and maximum building heights of an urban district.

\section{Keywords}

Energy Modeling; Parametric Simulation; Urban Context; Passive Survivability; Early Design; Resiliency; Peak-Load Reduction; Multi-Family Housing; Sensitivity Analysis; Cloud Simulation

\section{INTRODUCTION}

The United Nations expects the world's urban population to nearly double by 2050, increasing from 3.3 billion in 2007 to 6.4 billion in 2050, with much of this growth occurring in developing megacities [1]. Because of this new growth, society cannot afford to simply replicate standard building practices. New buildings must respond to the local climate and urban 
form, rather than rely on fossil fuels to make up for ill-suited designs. This is especially true in emergency events when utility grid-based systems may be unavailable.

Today, the American Institute of Architects and other organizations encourage design teams to use computerized simulation to achieve better energy performance in their projects [2]. However, many designers habitually apply this analysis too late in the process to take advantage of important design opportunities [3]. The most influential and costeffective decisions occur earliest in the project's life [4], and experts suggest that building energy simulation is most effective early in the design process $[5,6,7]$.

The following sections present a framework for the use of parametric energy simulation to inform early-stage building design and the use of this framework in a prototype, high-rise, residential building.

\subsection{The Case Study}

The prototype building was simulated in Beijing and Shenzhen China, chosen because they are fast growing megacities [8] representing two unique ASHRAE Climate Zones ( 2 and 4 respectively), as well as New York City also Zone 4 (included because of available, detailed urban context data). The authors performed a case study of a prototype residential high-rise building. They implemented a sensitivity analysis to identify the most influential of several early-stage design parameters -including building form, window-to-wall ratio, window shading, and others --considering a range of design options for each parameter.

\subsection{Parametric Simulation in Design}

Simulations traditionally used in the building industry require detailed inputs and, therefore, are difficult to employ in early design stages when the pace of design iteration is fast and the simulation inputs include many unknown variables [9]. By utilizing parametric simulation techniques with today's computing power, a modeler can evaluate numerous potential designs to produce guidance that design teams can use as an informed starting point in the design process.

Researchers have developed parametric simulation tools specifically for early design, [6, 10], such as BEOpt [11] from the National Renewable Energy Laboratory. These tools provide a user-friendly interface, but they present limitations with regard to suitable building types or available design inputs. Here, the authors propose a framework for utilizing parametric simulation in early design utilizing multiple existing tools (described in Section 3.6) offering the flexibility of user-defined design parameters and ranges.

\subsection{Methods}


Researchers have advanced the use of optimization techniques, such as genetic algorithms, in energy simulation [12, 13], which are computationally efficient and allow modelers to identify optimal solutions for quantifiable criteria from a large set of design combinations. Here, the authors chose an exhaustive search method, i.e. simulating all possible design combinations from a discrete search space. The exhaustive search method is computationally intensive but more suitable for creating design guidelines since the full solution space is available to the user, which allows her to combine optimization results with her own judgement. For example, the user can find/evaluate near-optimal design alternatives, not simply the optimum [11]. Furthermore, advancements in computation time and cloud-computing services give practitioners opportunities to search increasingly large sets of design combinations while keeping computation times and fees reasonable within real-world project budgets and scopes.

Researchers have developed [14] and implemented [15, 16, 17] sophisticated sensitivity analysis techniques for building thermal simulations. Some techniques perturb only one parameter at a time keeping other inputs constant [16] or use sampling techniques $[14,15,17]$, such as Monte Carlo methods, to perturb multiple inputs while simulating only a portion of the total possible design combinations. These methods prove especially valuable when computing power is limited or the set of possible combinations is very large. For this early-design investigation the authors prioritized a conceptually simple sensitivity analysis, made possible by the exhaustive search approach.

\subsection{Confounding Variables}

While existing research investigates the impact of design variables on energy objectives, most studies ignore the presence of potentially confounding variables, such as plug-loads (i.e. energy consumed by occupant appliances) and urban context. Although designers have little control over these parameters, these variables may warrant consideration, since they could influence the optimization of other parameters. Plug-loads have a high degree of uncertainty, occasionally varying by $100 \%$ or more over design estimates in practice [18], and they impact a building's heating and cooling loads.

Similarly, urban context affects energy use in buildings [19, 20, 21, 22]. In particular, Athalye [23] showed that the presence or absence of solar shading from neighboring buildings impacts design optimization. Here the authors similarly test the impact of solar obstructions on energy use and related design decisions, while expanding the investigation to include additional design parameters and more realistic urban contexts.

According to Reinhart and Davila [24], design teams, especially in the US, have increasing access to urban context data such as Geographic Information Systems (GIS) databases, LiDAR data, or other formats such as CityGML, which can be used to generate geometric models of a building's surroundings. However, particularly in fast growing megacities, design 
teams often need to design for (and policy-makers need to plan for) unknown context due to rapid development. Therefore, the authors propose using stochastic urban context models based on neighborhood-level density and building height restrictions.

\subsection{Performance Objectives}

Most building energy performance research focuses on annual energy consumption as the objective. Yet, due to peak-use tariffs, reducing a building's peak consumption can sometimes achieve greater utility cost savings than reducing annual consumption. Furthermore, as urban growth strains existing infrastructure [1] and the frequency and magnitude of weather emergencies increase, designers may have an ethical imperative to include other objectives. In this vein, researchers have begun to consider the impact of architectural design on both reducing peak loads [26, 27] and passive survivability [28, 29, $30]$.

Passive survivability is a type of resiliency. An important criterion of passive survivability is a building's ability to maintain an indoor temperature as close as possible to comfort conditions in a power outage, since extreme temperatures have been linked to increased mortality and morbidity in at-risk populations [31, 32]. Research on passive survivability is scarce and primarily focused on existing buildings. It remains unclear for designers how optimization for this and other energy-related objectives may differ. Therefore, in this study the authors compared the results of prioritizing three different

energy-related objectives: minimizing Energy Use Intensity (EUI), minimizing peak loads, and maximizing passive survivability (specifically the ability to passively maintain indoor temperatures) on early design decisions.

\section{THE TESTING AND ANALYSIS STEPS}

The authors propose the framework shown in Table 1 to perform the testing and analysis to inform early design decisions.

Table 1: The Analysis Framework

\begin{tabular}{|l|}
\hline Step 1: Select the objectives (e.g. minimize EUI) \\
\hline $\begin{array}{l}\text { Step 2: Choose design parameters and input values (e.g. } \\
\text { window-to-wall ratios of 30\%, 45\%, 60\%, and 75\%) }\end{array}$
\end{tabular}

Step 3: Consider potential confounding variables, i.e. variables that are not under the design team's control but may influence the performance of design parameters (e.g. external solar obstructions)

Step 4: Specify other model assumptions (e.g. operation schedules).

Step 5: Choose appropriate weather files (e.g. historic extreme weather years) 


\begin{tabular}{|c|}
\hline Step 6: Choose software (e.g. ArchSim and EnergyPlus) \\
\hline Step 7: Run parametric simulations \\
\hline $\begin{array}{l}\text { Step 8: Evaluate the objectives. Do they each } \\
\text { independently affect design decisions? }\end{array}$ \\
\hline $\begin{array}{l}\text { Step 9: Evaluate the confounding variables. Do they } \\
\text { affect the results and design decisions? }\end{array}$ \\
\hline $\begin{array}{l}\text { Step 10: Perform a sensitivity analysis to prioritize } \\
\text { design considerations }\end{array}$ \\
\hline $\begin{array}{l}\text { Step 11: Adjust the objectives, confounding variables, } \\
\text { and design parameters to better inform design. Repeat } \\
\text { Steps } 7-11 \text { as needed. }\end{array}$ \\
\hline $\begin{array}{l}\text { Step 12: Use the results to inform early design. Identify } \\
\text { important design considerations and preferred ranges of } \\
\text { parameter values. }\end{array}$ \\
\hline $\begin{array}{l}\text { (Continue to use simulation best practices to inform the } \\
\text { remaining design process.) }\end{array}$ \\
\hline
\end{tabular}

\section{THE CASE STUDY}

\subsection{Step 1: Selecting the Objectives}

As explained in Section 1, the authors chose three different energy-related objectives: minimizing Energy Use Intensity (EUI), minimizing peak loads, and maximizing passive survivability. Here, EUI (i.e. annual energy consumption per unit floor area) includes only heating cooling and lighting energy. "Peak loads" refer to the peak heating and cooling power demand for each design variant, since the other end-uses remained constant between the design cases.

To test passive survivability, the authors ran each simulation for two weeks. The first week followed a normal operation schedule. Then the heating, cooling, and plug-loads switched off (resembling a power outage) and the simulation ran for an additional week. The authors recorded the indoor operative temperatures ${ }^{1}$, in one thermal zone of the building - the hottest zone in summer and the coldest zone in winter. The authors found the design case in each city that keeps this zone the closest to comfort conditions.

\subsection{Step 2: Choosing the Design Parameters and Input Values}

For this case study, the parameters tested included various early-design-phase decisions, such as building shapes, windowto-wall ratios ${ }^{2}$ (WWR), envelope constructions, and shading designs, as listed in Table 2. Here, the baseline architectural

\footnotetext{
1 "Operative temperature" is a measure of human comfort that combines air temperature and mean radiant temperature.

2 i.e. the glazing area to wall area ratio of the building's envelope
} 
parameters met ASHRAE 90.12010 standards [33], except for the maximum 40\% WWR limitation, because contemporary buildings frequently exceed this limitation.

To determine what impact building shape might have on the energy results, the authors modeled three different plan shapes, chosen because they varied in perimeter area and the potential for self-shading. They included a long-thin rectangle (1-to-3.5 width to length ratio), a "square" (actually a 1-to-1.67 width to length ratio, since truly square floor plans are rare in residential high-rise architecture), and a T-shape. Each shape contained the same floor area. The dimensions were determined using commercial standards such as double-loaded corridors and a center-to-perimeter distance of $10 \mathrm{~m}$ (33ft), which is a reasonable assumption for residential buildings (especially those built above underground parking garages). Per simulation best practices [33], each plan was divided into thermal zones by core, perimeter (4.6m [15 ft] wide), and solar orientation. See Figure 1.

Table 2: Parameters Tested

\begin{tabular}{|l|l|}
\hline \multicolumn{1}{|c|}{ Input Name } & \multicolumn{1}{|c|}{ Parameter Values } \\
\hline Building Shape & See Figure 1 \\
\hline $\begin{array}{l}\text { Building } \\
\text { Orientation) }\end{array}$ & \\
\hline
\end{tabular}




\begin{tabular}{|c|c|}
\hline $\begin{array}{l}\text { U-Value } \mathrm{W} / \mathrm{m}^{2} \mathrm{~K} \\
\mathrm{R}-\text { Value } \\
\left(\mathrm{ft}^{2} \mathrm{~F} \text { hr/ Btu }\right)\end{array}$ & $\begin{array}{l}\text { polystyrene (XPS)- } 0.09 \mathrm{~m} \text {, concrete- } 0.12 \mathrm{~m} \\
\text { "More Insul.": Assembly } \mathrm{U}=0.22(\mathrm{R}=25.8) \text { Layers } \\
\text { and thicknesses: concrete- } 0.12 \mathrm{~m} \text {, XPS- } 0.15 \mathrm{~m} \text {, } \\
\text { concrete- } 0.12 \mathrm{~m} \\
\text { "Most Insul.": Assembly } \mathrm{U}=0.15(\mathrm{R}=37.8) \text { Layers } \\
\text { and thicknesses: concrete- } 0.12 \mathrm{~m} \text {, vacuum panel, } \\
\text { concrete- } 0.12 \mathrm{~m}\end{array}$ \\
\hline Thermal Mass & $\begin{array}{l}\text { "Low Thermal Mass": see exterior wall description } \\
\text { above, with .25m (9.8in) thick concrete ceiling and } \\
\text { floor } \\
\text { "High Thermal Mass": same as above with double } \\
\text { thickness concrete in ceiling }\end{array}$ \\
\hline $\begin{array}{l}\text { Plug-Loads } \\
\mathrm{kWh} / \mathrm{m}^{2} \\
\left(\mathrm{kBtu} / \mathrm{ft}^{2}\right)\end{array}$ & $\begin{array}{l}\text { "Low Internal Loads": } 5.5(1.74) \\
\text { "High Internal Loads": } 11(3.49) \\
\text { The plug-load diversity schedule is listed in appendix } \\
\text { A. }\end{array}$ \\
\hline
\end{tabular}

*Glass ASHRAE = ASHRAE 90.12010 [33] maximum U and SHGC values.

** Wall ASHRAE = ASHRAE 90.1 2010 [33] Zones 2 and 4 maximum wall assembly U values (same requirements for both climate zones)

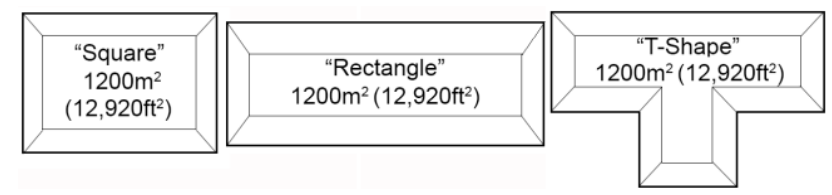

Figure 1: Plan shapes with typical thermal zoning

\subsection{Step 3: Considering Potential Confounding Variables}

Here, confounding variables are defined as model parameters that the modeler wishes to test that are not under the design team's control. These variables may affect the performance of design parameters and, therefore, design decisions. Here the authors investigated confounding variables: plug-loads and urban context.

\subsubsection{Plug-Loads}

The authors tested the design parameters with two levels of plug-loads. They chose a baseline called "Low Internal Loads" per the U.S. DOE's Commercial Prototype Building Models (based on ASHRAE 90.1 2004) [34] as shown in Table 2. They then doubled that value to reflect the uncertainty of real-world inputs found in past research [18].

\subsubsection{Urban Context}

Here, the authors conjectured whether it is critical to model urban context, as a source of sun shading, for this presimulated design resource. The presence of neighboring buildings would change energy use, but would it also change the preferred design decisions? To test the impact of urban context, the authors first simulated the 12,096 different design combinations without surrounding buildings, then again within an urban context (the "generalized high-density context" described below). They repeated this study for Beijing, New York City, and Shenzhen, and compared the results with and 
without context. For this parametric analysis, the authors simulated a lower floor (15m [50ft] above ground) of a high-rise, which would be susceptible to shading from neighboring buildings.

Assuming that context matters, one faces a challenge when creating generalized pre-design guidance in cities, since a modeler cannot know where in an urban district a future building may be located. Therefore, the authors developed a script in Grasshopper for generalizing urban context. The algorithm uses a fixed lot and street size then randomizes neighboring building heights while maintaining a district's maximum Floor Area Ratio (FAR) and height limits (see Figure 2).

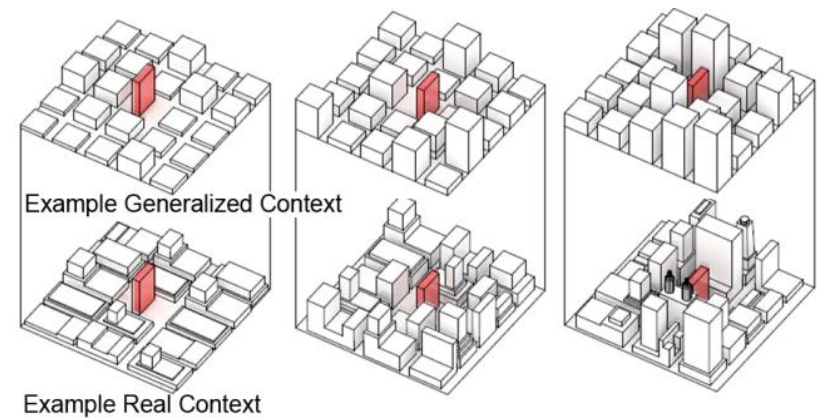

Figure 2: Example Generalized Context

Next, the authors evaluated this method of generalizing urban context. They chose three different neighborhoods in New York City as test cases and produced detailed geometric models, labeled "real" context, as shown in Figure 3. These sites included: (1) a high-density context with a Floor-Area-Ratio (FAR) of 15 and a maximum building height limit of 180 meters, (2) a medium-density context with an FAR of 6 and a maximum building height limit of 120 meters, and (3) a lowdensity context with an FAR of 6 and a maximum height limit of $65 \mathrm{~m}$. The authors hypothesized that in these cases simulating the building with a generic context would introduce some error, when compared to the "real" context models, but would improve accuracy over the customary approach of using no context.

To test this hypothesis, they performed the parametric simulations with the real context, the generic context, and no context then compared results. They also repeated this stochastic process to create 50 different urban contexts, in order to investigate the impact of various arrangements of solar obstructions. The context analysis is explained further in Section 3.9.2. 


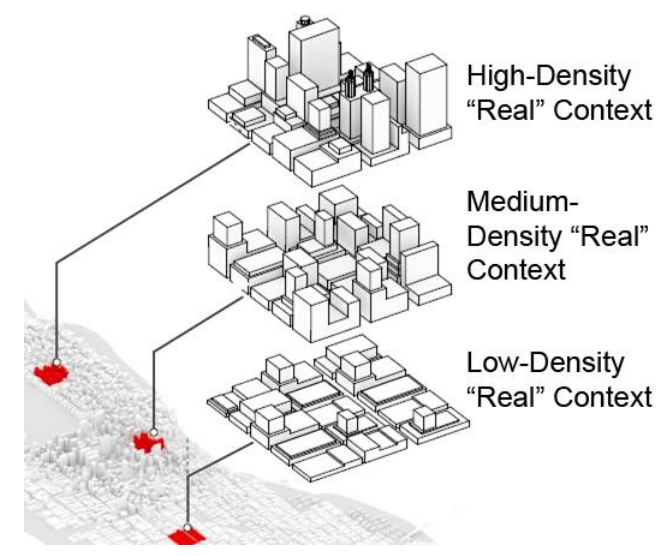

Figure 3: "Real" Context Models in New York

\subsection{Step 4: Specifying Other Model Assumptions}

Modelers must specify the other, non-perturbed, model inputs, and should be aware of software default settings. Model assumptions can have a large impact on the applicability of the results. In addition to the parameters described above, Appendix A lists several key model assumptions used here. The simulations assumed an ideal load system with mechanical ventilation. (For calculating EUI, the authors assumed a heating and cooling coefficient of performance of 1.0.)

\subsection{Step 5: Choosing the Weather Files}

For the EUI and peak-load objectives, the authors chose to study the design impacts in typical weather years to design for high-probability conditions. In contrast, passive survivability research aims to promote safety in extreme events. Since typical weather files are created by compiling the least extreme months of historic weather data from a multi-year range [35] these weather files would be inadequate for studying passive survivability. Therefore, the authors performed these simulations using extreme meteorological year (XMY) weather files, following Crawley and Lawrie's methodology [36] by choosing historical weather files from the available range (2001 to 2014) with the highest and lowest hourly dry-bulb temperature. ${ }^{3}$ In order to consider long-term climate-change impacts modelers could also morph existing typical weather files into future weather files, using the method of Hacker et al [37] for example. However, the objective here is to study near-term extreme events rather than distant future climactic trends.

Details of the simulation dates and weather conditions are shown in Table 3. For the power outage, the authors chose the "extreme week", i.e. the week nearest the maximum or minimum (dry bulb) temperature for the year, as identified in the weather file header.

\footnotetext{
${ }^{3}$ The authors found the year with the hottest/coldest historic hourly temperature for each city using www.wunderground.com. In case of a tie, they used the year with the most extreme week, based on number of cooling or heating degree days. They then obtained .epw files for the selected years from weather.whiteboxtechnologies.com/hist.
} 
Table 3: Details of Passive Survivability Simulations

\begin{tabular}{|l|l|l|}
\hline \multicolumn{1}{|c|}{ Weather File } & Power Outage Dates & \multicolumn{1}{|c|}{$\begin{array}{c}\text { Extreme Outdoor } \\
\text { Dry-Bulb } \\
\text { Temperature }\end{array}$} \\
\hline $\begin{array}{l}\text { Beijing extreme cold: } \\
2010\end{array}$ & January 08 to 14 & $-19^{\circ} \mathrm{C}\left(-2^{\circ} \mathrm{F}\right)$ \\
\hline $\begin{array}{l}\text { Beijing Extreme hot: } \\
2014\end{array}$ & July 17 to 23 & $42^{\circ} \mathrm{C}\left(107^{\circ} \mathrm{F}\right)$ \\
\hline $\begin{array}{l}\text { New York extreme } \\
\text { cold: } 2004\end{array}$ & January 19 to 25 & $-17^{\circ} \mathrm{C}\left(1{ }^{\circ} \mathrm{F}\right)$ \\
\hline $\begin{array}{l}\text { New York extreme } \\
\text { hot: } 2011\end{array}$ & July 20 to 26 & $39^{\circ} \mathrm{C}\left(103^{\circ} \mathrm{F}\right)$ \\
\hline $\begin{array}{l}\text { Shenzhen extreme } \\
\text { cold Not investigated due to mild winter conditions. }\end{array}$ & June 28 to July 04 & $38^{\circ} \mathrm{C}\left(100^{\circ} \mathrm{F}\right)$ \\
\hline $\begin{array}{l}\text { Shenzhen Extreme } \\
\text { hot: } 2004\end{array}$ & Jun \\
\hline
\end{tabular}

\subsection{Step 6: Choosing the Software}

The authors linked several different tools together to create the parametric model. They used EnergyPlus [38], a wholebuilding energy performance simulation engine developed by the U.S. Department of Energy. EnergyPlus is a free and open-source engine, which offers advanced energy simulation capabilities [39], including multi-zone, sub-hourly, heat and mass transfer calculations.

For daylight simulation, this version of EnergyPlus relies on the split-flux method, which is faster but less accurate than the ray tracing method employed by the lighting simulation tool Radiance [40]. Athalye et al [23] demonstrated in a similar case study investigation that the EnergyPlus method is adequate for evaluating the energy impacts of daylighting and exterior obstructions compared to a more arduous practice incorporating Radiance.

Since the goal was to create a resource integrated with the early-design process, the authors sought an interface that could link to modeling software already used by many designers. Therefore, the parametric building model, the urban context model, and the code used to iterate through all the simulations was created in Grasshopper. Grasshopper [41] is a graphical algorithm editor enabling parametric 3D modeling in the popular 3D computer-aided design program Rhinoceros [42]. The authors used ArchSim [43], a Grasshopper-based plug-in to convert the building model information into input files for EnergyPlus. The energy simulation file was automatically uploaded from Grasshopper to a customized web service [44] where the simulations were executed in the cloud. The results were compiled into Comma Separated Values for use in Excel.

\subsection{Step 7: Running the Simulations}

In order to investigate the importance of each parameter and provide information for analysis, the authors simulated every permutation of the design parameters. After each phase of the study, they performed a preliminary sensitivity analysis, as 
described in Section 3.10, to determine which design parameters warranted a more- or less- thorough investigation. Next, they adjusted the number of perturbations to provide the most beneficial information while maintaining feasible computation time. Figure A1 in Appendix A shows an overview of the case study research. Table 4 lists the number of design permutations tested in each phase (not including the preliminary analysis), for a total of 90,820 simulations. The following sections present the results of the case study simulations.

Table 4: Number of Simulations Tested in Each Phase

\begin{tabular}{|l|}
\hline EUI and Peak Load Analysis: \\
12,096 permutations x 3 cities $=36,288$ simulations \\
\hline Passive Survivability Analysis: \\
6,048 permutations* x 5 weather files (Beijing Summer, \\
Beijing Winter, New York Summer, New York Winter, \\
Shenzhen) \\
$=30,240$ \\
\hline EUI and Peak Load Analysis with Urban Context: \\
New York REAL context $=3,024$ permutations $* * \quad$ x \\
3 (High, Medium, Low) densities $=9,072$ \\
New York GENERIC context $=3,024$ x 3 (High, \\
Medium, Low) densities $=9,072$ \\
Shenzhen $=3,024$ \\
Beijing $=3,024$ \\
\hline Randomized Context Analysis: \\
50 randomized contexts $x 2$ permutations (best and worst \\
EUI cases from above) $=100$ \\
\hline Total: \\
90,820 Simulations
\end{tabular}

* high plug-load cases removed

** high plug-load cases and high thermal mass cases removed

\subsection{Step 8: Evaluating the Objectives}

Here, the authors sought to understand whether the range of parameters tested would substantially impact building performance according to each objective. Also, since all three objectives were similar, i.e. all related to energy performance, the authors questioned whether each of these objectives would prove to be important to consider, or if some of the objectives would provide redundant guidance to designers.

\subsubsection{EUI and Peak Load Results}

The design parameters and ranges studied here had a substantial impact on each of the energy objectives studied. Table 5 lists the difference between the best and worst performing design cases for EUI and peak loads. Figures 4 and 5 show the results in more detail (with and without urban context, which will be discussed in Section 3.9.2). One can see a difference 
ranging from $18-42 \%$ between the best and worst performing design cases for each objective in each city. ${ }^{4}$

Table 5: Difference between Best and Worst Design Cases

\begin{tabular}{|c|c|c|c|}
\hline & Beijing & $\begin{array}{c}\text { New } \\
\text { York }\end{array}$ & Shenzhen \\
\hline EUI & $19 \%$ & $18 \%$ & $21 \%$ \\
\hline Peak Cooling Load & $36 \%$ & $42 \%$ & $22 \%$ \\
\hline Peak Heating Load & $19 \%$ & $19 \%$ & NA \\
\hline
\end{tabular}

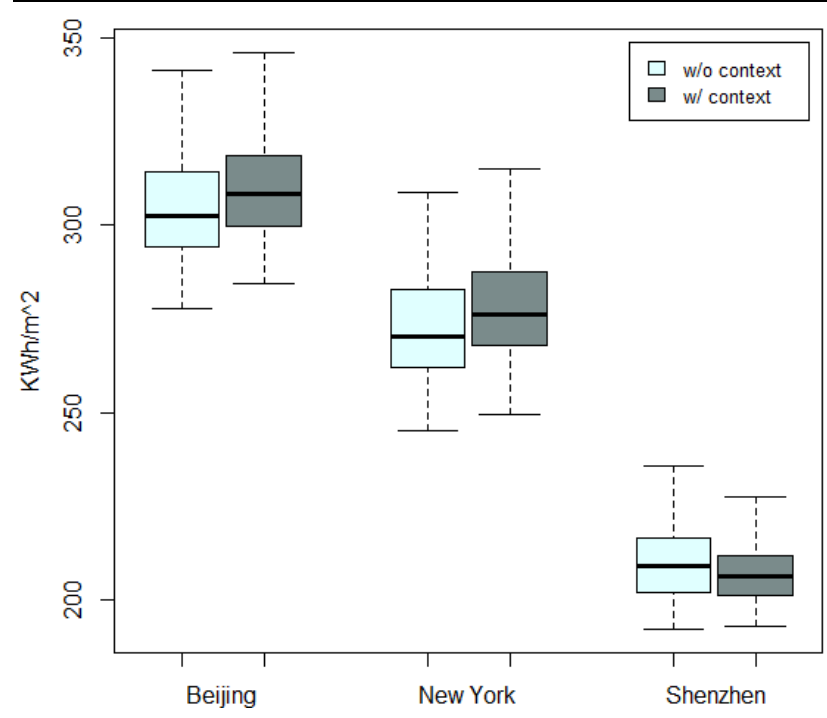

Figure 4: Box Plot of EUI Results in Each City

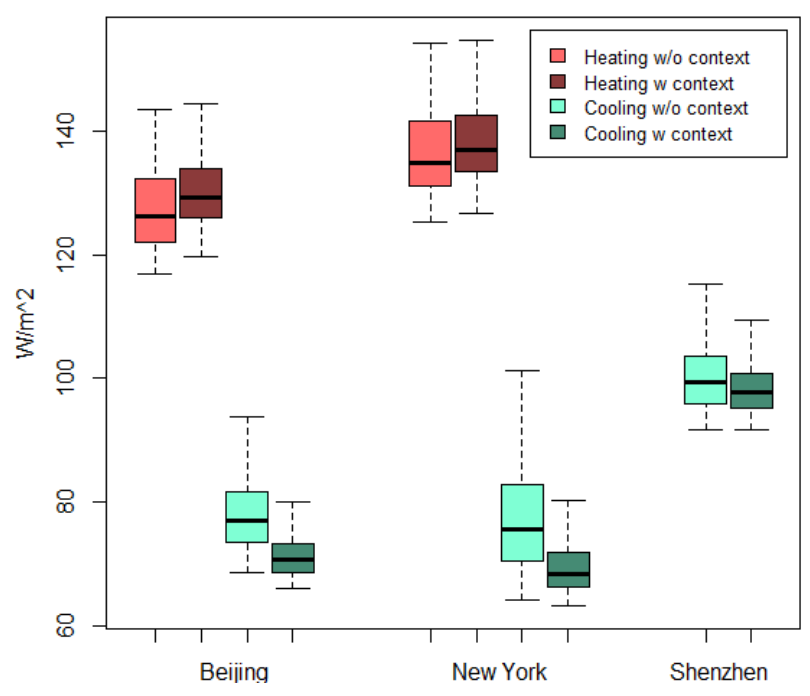

Figure 5: Box Plot of Peak Heating and Cooling Loads in Each City

\subsubsection{Passive Survivability Results}

\footnotetext{
${ }^{4}$ The results shown/discussed throughout include the low plug-load cases only.
} 
The passive survivability objective also revealed a substantial difference in performance between the designs studied here.

Table 6 summarizes the difference in extreme indoor operative temperature recorded for the best and worst performing designs during the simulated power outage.

Table 6: Passive Survivability Difference between Best and Worst Design Cases

\begin{tabular}{|c|c|c|c|}
\hline & Beijing & $\begin{array}{c}\text { New } \\
\text { York }\end{array}$ & Shenzhen \\
\hline $\begin{array}{c}\text { SUMMER Extreme Indoor } \\
\text { Operative Temperature: delta } \\
\text { between best \& worst cases }\end{array}$ & $\begin{array}{c}\Delta 9^{\circ} \mathrm{C} \\
\left(17^{\circ} \mathrm{F}\right)\end{array}$ & $\begin{array}{c}\Delta 9^{\circ} \mathrm{C} \\
\left(16^{\circ} \mathrm{F}\right)\end{array}$ & $\begin{array}{c}\Delta 11^{\circ} \mathrm{C} \\
\left(20^{\circ} \mathrm{F}\right)\end{array}$ \\
\hline $\begin{array}{c}\text { WINTER Extreme Indoor } \\
\text { Operative Temperature: delta } \\
\text { between best \& worst cases }\end{array}$ & $\begin{array}{c}\Delta 7^{\circ} \mathrm{C} \\
\left(13^{\circ} \mathrm{F}\right)\end{array}$ & $\begin{array}{c}\Delta 6^{\circ} \mathrm{C} \\
\left(11^{\circ} \mathrm{F}\right)\end{array}$ & NA \\
\hline
\end{tabular}

Figures 6,7 , and 8 show the simulation results in more detail. ${ }^{5}$ (Beijing's results were similar to New York's.) The graphs illustrate the difference between the best and worst design in terms of mitigating indoor temperature extremes. One can see a substantial performance difference between the design cases, especially in the summers. (Figures 6, 7, and 8 also show the performance of the EUI-optimized design case, which will be discussed in Section 3.8.3.) The outdoor temperature is plotted for reference.

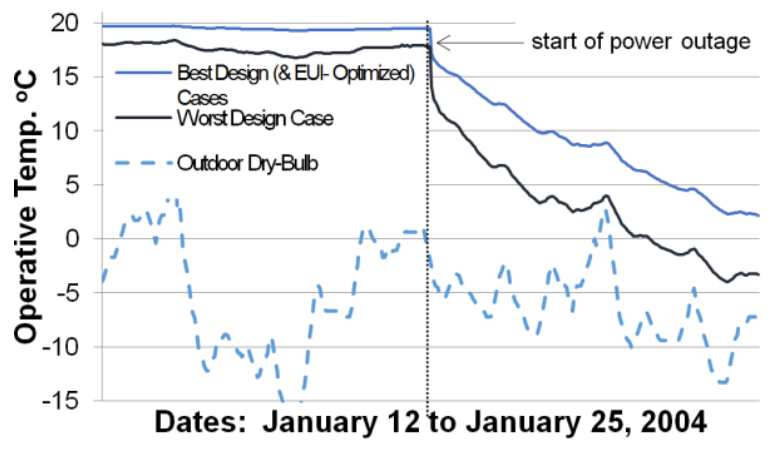

Figure 6: Indoor Operative Temperatures in New York with Simulated One-Week Winter Power Outage, Best and Worst Designs

\footnotetext{
${ }^{5}$ The following is an explanation of the temperature phenomena shown here. Prior to the power outage, the indoor air temperature does not exceed (or drop below) the thermostat set-point in summer (and winter respectively). However, the operative temperature, shown here, is also influenced by surface temperatures, especially in design cases with large areas of poor-performing glass, which is why the temperature shown here does not appear to be bound by the thermostat, even prior to the power outage. During the power outage, the indoor temperatures are no longer mitigated by heating and cooling systems, and plug-loads, which produce heat as a by-product, are eliminated.
} 


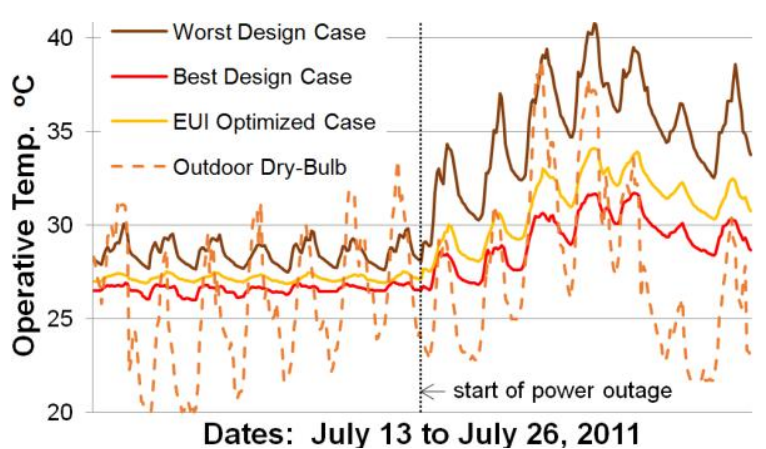

Figure 7: Indoor Operative Temperatures in New York with Simulated One-Week Summer Power Outage, Best and Worst Designs

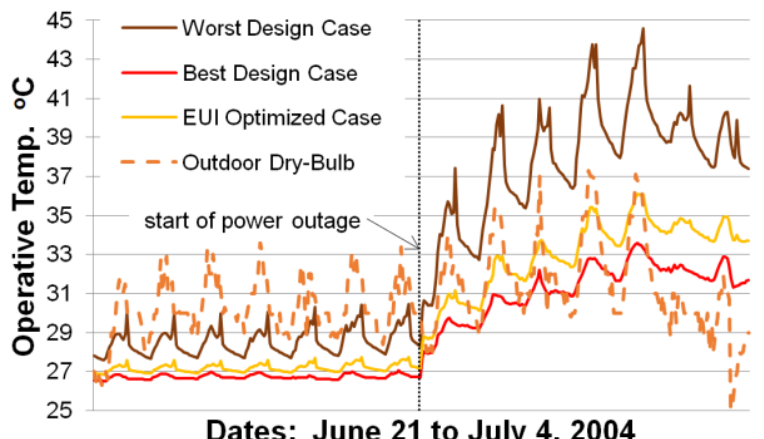

Dates: June 21 to July 4, 2004

Figure 8: Indoor Operative Temperatures in Shenzhen with Simulated One-Week Summer Power Outage, Best and Worst Designs

\subsubsection{Relevance of Objectives as Decision-Criteria}

With such a large discrepancy in performance between different design cases, so far none of the three performance objectives can be deemed trivial. Next, a design team might wonder if each objective would provide additional design guidance, or if some objectives might provide redundant information.

Figures 9, 10, and 11 show the energy end-uses for a sampling of the design cases. One can see that cooling consumption dominated the energy use in Shenzhen, while the heating consumption was small. The lighting consumption was both small and relatively stable across the design cases. Therefore, optimizing for low EUI or low peak cooling loads was redundant here; both objectives resulted in the same building design. Table A2 in the Appendix lists the winning design parameters, of those tested here, for different objectives.

Similarly, the EUI and peak heating objectives were somewhat redundant here for New York and Beijing. In New York the optimal peak heating design was the "square" building, whereas the optimal EUI design was the "rectangular" building; however, either shape worked well for both objectives, affecting the performance by less than $1 \%$. Similarly, in Beijing and New York, as shown in Figure 6, optimizing for passive survivability in the winter produced almost no change or benefit over optimizing for EUI. 


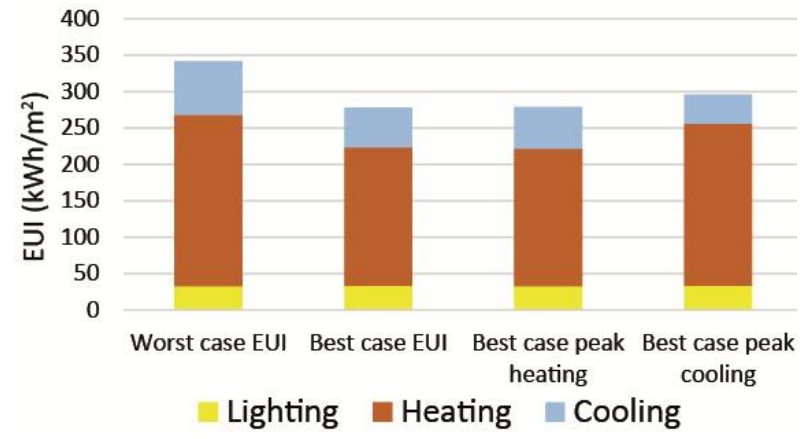

Figure 9: Energy Breakdown of Notable Design Cases, Beijing

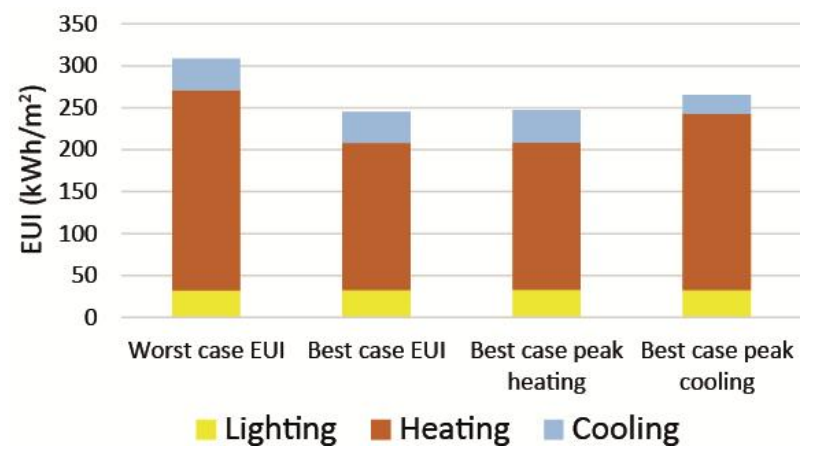

Figure 10: Energy Breakdown of Notable Design Cases, New York

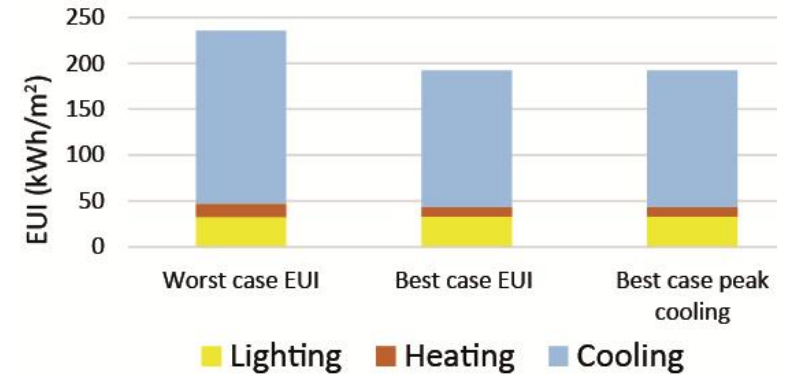

Figure 11: Energy Breakdown of Notable Design Cases, Shenzhen

Figures 7 and 8 show how well the EUI-optimized design case performed in a summer-time power outage, compared to the passive survivability-optimized case. Contrary to the previously-described trends, even in cooling-dominant Shenzhen, EUI was not a good proxy for summertime passive-survivability and vice versa. The EUI-optimized case performed $2.5^{\circ} \mathrm{C}$ worse at the most extreme than the passive survivability-optimized case. ${ }^{6}$ Without simulation, this trend may not have been apparent. The implications of these findings on the next steps of the investigation are discussed in Section 3.11.

\subsection{Step 9: Evaluating the Confounding Variables}

\subsubsection{Relevance of Plug-Loads}

The "high" versus "low" plug-loads affected the balance of heating and cooling loads in the space. For example, in New

\footnotetext{
${ }^{6}$ In turn, the passive survivability-optimized case performed poorly ( $4 \%$ worse) in EUI compared to the design case optimized for EUI.
} 
York increasing plug-loads from 5.5 to $11 \mathrm{kWh} / \mathrm{m}^{2}\left(1.74\right.$ to $\left.3.49 \mathrm{kBtu} / \mathrm{ft}^{2}\right)$ reduced the heating load by $14 \%$ and increased the cooling load by $42 \%$. However, plug-loads were not found to be an important variable here, because they did not affect the preferred selection of design parameters. Therefore, the authors eliminated this variable in later stages of the research. Because of the impact on heating and cooling loads, the plug-load variable might become an important consideration later in the design process, for example when testing HVAC energy conservation measures.

\subsubsection{Impact of Urban Context on Performance}

This research supports the notion that in some urban contexts, the shading cast by neighboring buildings can act as an important confounding variable. ${ }^{7}$ Here, including the generalized high-density urban context in the simulations substantially affected the annual energy use, as illustrated in Table 7 and Figure 12 for the 3024 design cases tested in each climate. Even the impact of the low-density urban context was substantial. In New York, including the low-density generic context increased the annual heating use by $1 \%$, while decreasing the annual cooling use by $11 \%$, on average, compared to iterations with no context.

Table 7: Energy Use: Change from No Context to High-Density Generic Urban Context (mean of 3024 design cases)

\begin{tabular}{|l|c|c|c|}
\hline & Beijing & New York & Shenzhen \\
\hline Lighting & $8 \%$ & $8 \%$ & $8 \%$ \\
\hline Heating & $7 \%$ & $8 \%$ & NA \\
\hline Cooling & $-20 \%$ & $-31 \%$ & $-3 \%$ \\
\hline
\end{tabular}

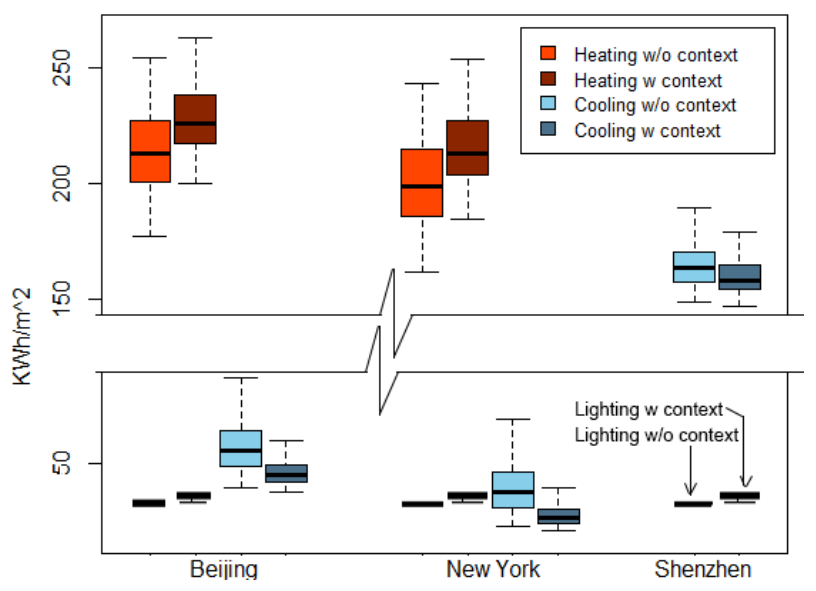

Figure 12: Impact of (High-Density Generic) Context on Annual Heating, Cooling, and Lighting

Figure 13 shows the impact of the various context forms tested in New York City. One can see that in each case, as

\footnotetext{
${ }^{7}$ Modeling additional urban context effects, which were outside the scope of this research, such as the reflectivity of neighboring facades and heat island effects may impose additional impacts on building performance.
} 
expected, the generalized contexts produced slightly different results than the "real" contexts. However, the differences were small, and in every case (considering lighting, heating, and cooling end-uses in the different urban densities) the generalized contexts produced smaller errors $(0-11 \%)$ than ignoring urban context altogether $(8-31 \%)$. Therefore, creating a generalized urban context based on known urban characteristics produced substantially better results than ignoring urban context altogether.

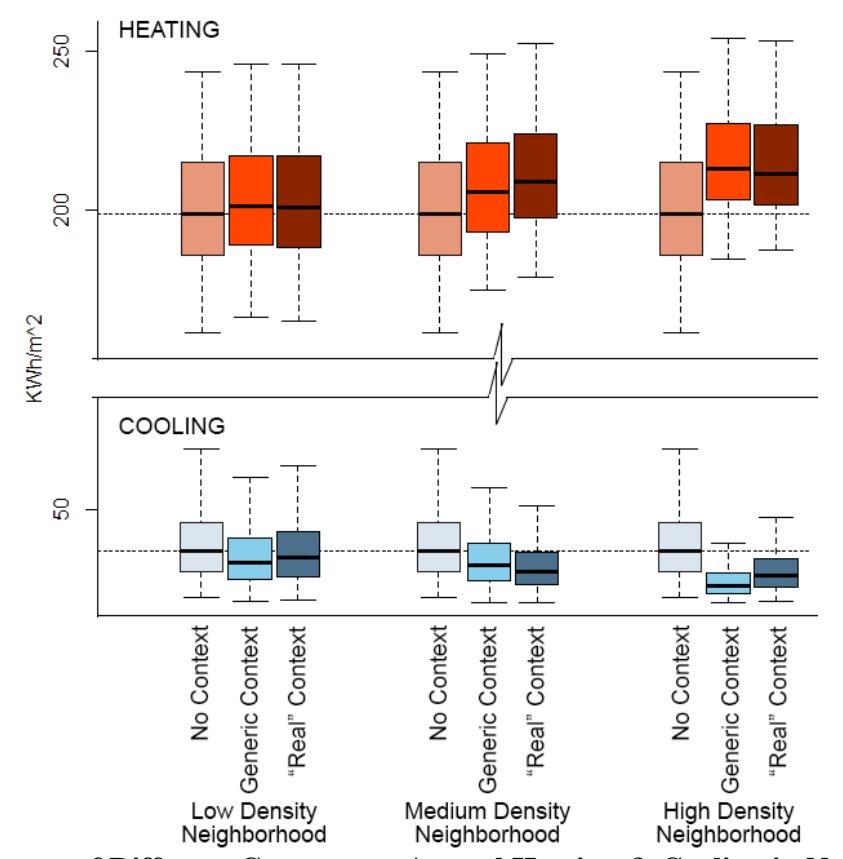

Figure 13: Impact of Different Contexts on Annual Heating \& Cooling in New York City

Here the authors used an algorithm to choose neighboring building heights stochastically. An anomaly in any one urban context iteration would impact the results. To hedge against this type of experimental artifact, the authors repeated the stochastic process numerous times to generate several potential urban contexts. Modelers and policy-makers could also use this method to test the robustness of design decisions in various urban scenarios.

The authors demonstrated this method by generating 50 different high-density urban conditions. They then simulated two design cases (the best- and worst- performing EUI cases) in each context. ${ }^{8}$ Table 8 shows the results. One can see how the performance of the low-performance design case is much more susceptible to variations in urban context than the highperformance design case but only in terms of heating and cooling loads. Even though all cases included continuous dimming lighting controls, as shown in Table A1, meaning that the electric lighting power density responded to interior

\footnotetext{
${ }^{8}$ This method was computationally intensive. Therefore, the authors limited the test to 100 simulations rather than testing every design case.
} 
daylight illuminance levels, the lighting loads proved to be relatively stable across the various building designs and urban contexts.

Table 8: Range of Simulation Results with 50 Different Urban Contexts

\begin{tabular}{|l|c|c|}
\hline & $\begin{array}{c}\text { Range } \mathbf{k W h} / \mathbf{m}^{2} \text { (and } \\
\text { standard deviation) best } \\
\text { performing design } \\
\text { case* in different } \\
\text { contexts }\end{array}$ & $\begin{array}{c}\text { Range } \mathbf{k W h} / \mathbf{m}^{2} \text { (and } \\
\text { standard deviation) } \\
\text { worst performing } \\
\text { design case** in } \\
\text { different contexts }\end{array}$ \\
\hline Lighting & $33-35(2)$ & $33-35(2)$ \\
\hline Heating & $182-190(9)$ & $234-247(12)$ \\
\hline Cooling & $29-33(4)$ & $34-43(12)$ \\
\hline
\end{tabular}

*Rectangle, $180^{\circ}$ rotation, 30\% WWR, High-Perform. Glass, Most Insulation Wall

** Rectangle, $60^{\circ}$ rotation, $75 \%$ WWR, ASHRAE Glass, Wall ASHRAE

\subsubsection{Relevance of Urban Context to Design}

Importantly, urban context also affected the preferred design decisions. For example, Figures 14 and 15 show how the preferred design parameters for the low-EUI objective changed with the addition of the high-density context to the model. In New York (and Beijing) the preference for window shading was eliminated. In Shenzhen, the addition of high-density context changed the preferred Building Shape and Solar Orientation while eliminating the preference for Window Shading.

In summary, including urban context mattered. Because several important design decisions changed depending on whether or not context was included, in some cases pre-design guidance (and energy code requirements) should account for the shading effects of urban context.

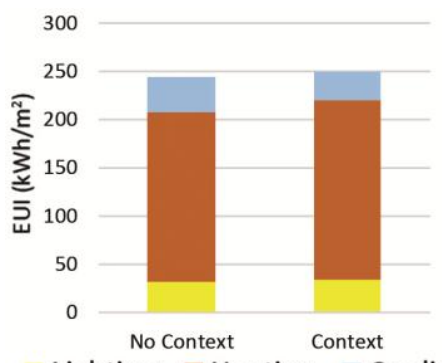

Lighting Heating Cooling
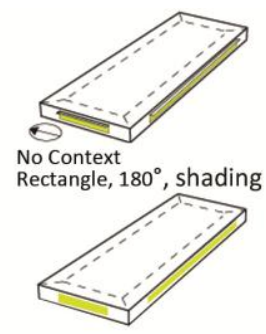

With Context
Rectangle, $180^{\circ}$, no shading

Figure 14: Lowest EUI Case with/without Context, New York
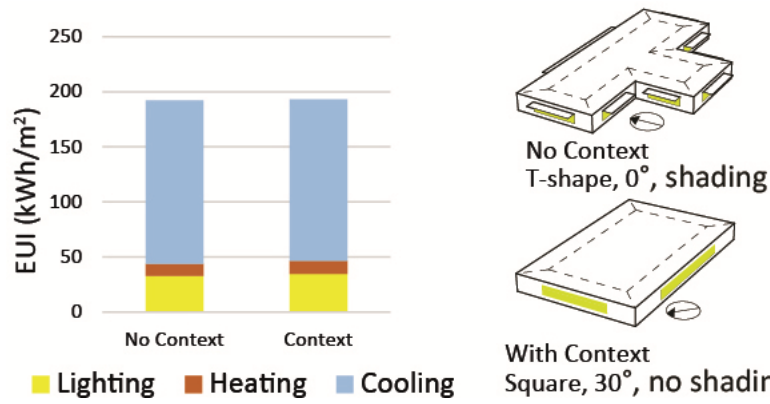

With Context

Square, $30^{\circ}$, no shading 


\section{Figure 15: Lowest EUI Case with/without Context, Shenzhen}

\subsection{Step 10: Performing a Sensitivity Analysis}

To inform the methodology for a pre-simulated design resource, the authors ranked the design parameters by their impact on the objectives via a sensitivity analysis. Here, the sensitivity index for each parameter was calculated per Equation 1. Sensitivity analysis is a method for decision-makers to establish design priorities. For example, within the parameters and ranges tested here, EUI proved to be particularly sensitive to the selection of window-to-wall-ratio.

where:

$$
\text { Sensitivity Index } x_{W W R}=\frac{\tilde{x}_{w o r s t}-\tilde{x}_{\text {best }}}{\tilde{x}_{\text {worst }}} \times 100 \%
$$

Sensitivity Index $\boldsymbol{W}_{W \mathrm{R}}=$ the sensitivity of the

Energy Use Intensity (EUI) to the selection of WWR within

the range of values tested

$\tilde{\boldsymbol{x}}_{\text {best }}=$ median EUI of all the design combinations

that included the best performaing value of WWR

$\widetilde{\boldsymbol{x}}_{\text {worst }}=$ median EUI of all the design combinations

that included the worst performaing value of WWR

\section{Equation 1: Sensitivity Analysis of Test Parameters}

The results are shown in Figure 16 for each city with and without the generalized high-density urban context. Of the parameters tested, EUI was most sensitive to WWR, Glass Type, Building Rotation, (Window Shading, particularly in Shenzhen without urban context), Building Shape, and Wall Insulation, in that order. It is important to note that, like most sensitivity analyses, the ranking is only representative for the parameter ranges of the simulation study. For instance, a narrow spread of thermal resistance for the wall insulation and a wide spread for WWR will prioritize WWR over wall insulation. However, for a wide spread of the wall insulation, and a narrow spread for WWR, the priorities may change. 


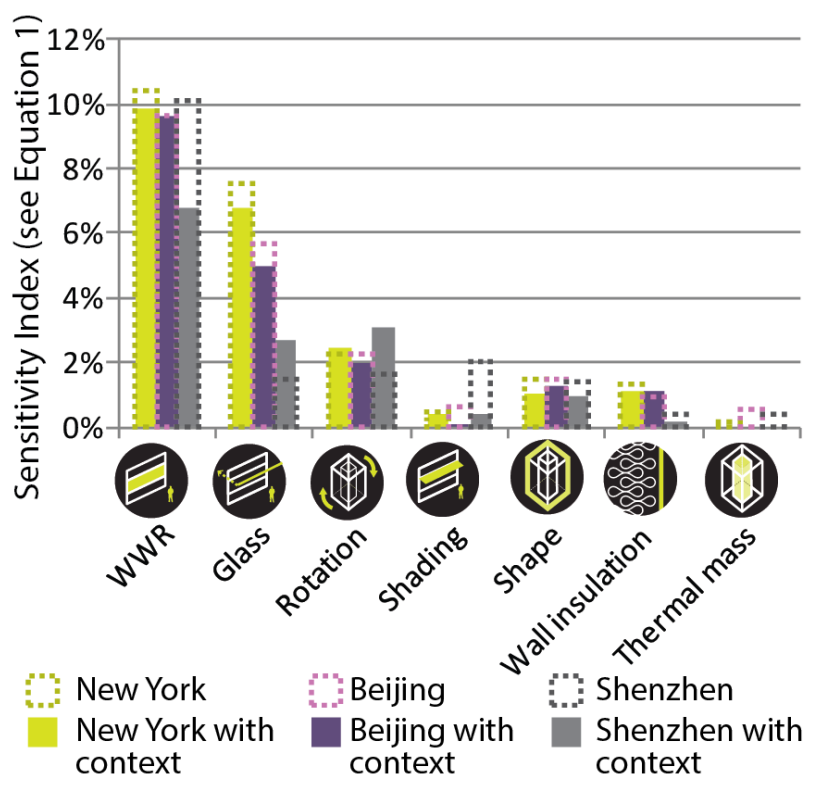

Figure 16: Sensitivity of EUI to Design Parameters

When tested, the higher thermal mass option always produced better results according to the objectives. However, changing the levels of thermal mass did not produce a large impact on the simulated results. Two factors likely contributed to this result. First, even the "Low Mass" option included exposed concrete surfaces, and thus already had high thermal mass relative to lightweight construction choices. Second, due to the indoor daylight settings used in EnergyPlus, the added thermal mass in the "high mass" option was not exposed to direct sunlight, which limited its simulated effectiveness. This and other limitations of this approach will be discussed in Section 4.2.

\subsection{Step 11: Adjusting the Parameters and Repeating}

The parametric simulation process will likely take multiple iterations, even in early design. Modelers should adjust the process throughout to provide the most valuable information with the available (human and computational) resources.

Here, the authors investigated the "design significance" of design parameters, objectives, and confounding variables. They defined "design significance" by asking: does this variable change the choice a designer should make, and would that selection then significantly impact the building's performance? For example, varying plug-loads had a very large impact on heating/cooling/lighting loads. However, here the presence of high or low plug-loads would not change an architect's selection of the design parameters tested.

As mentioned in Section 3.7, here the authors performed preliminary simulations and sensitivity analyses. Based on these results they expanded the test ranges for parameters found to be significant, including WWR, Glass Type, and Solar Orientation to include the values listed in Table 2. As discussed in Sections 3.7 and 3.9.1, in later phases of this research, 
the authors removed test values for Plug-Loads and Thermal Mass since, within the ranges tested here, they lacked design significance.

\subsection{Step 12: Informing Early Design}

The quantitative results of the parametric simulation analysis can be used to help set energy performance targets for the project moving forward. For example, the team could target improvements over a baseline based on the range of results produced by the design cases.

In addition, simulation can not only assist teams in identifying the most influential design parameters, as discussed in Section 3.10, but also shedding light on the preferred ranges for key design parameters in early design. Since the whole solution set is available for analysis, reviewing this data can help identify trends and interactions between the different design parameters. The following section describes some examples from this analysis.

Within the parameters and ranges tested here, window-to-wall ratio emerged as the most important design consideration, and a smaller WWR outperformed a larger WWR in every city, context, and combination of design parameters. Designers struggle with WWR selection in particular since non-energy objectives including views, aesthetics, and occupant preferences often favor larger WWR. The results here showed that in Beijing and New York, even a 75\% WWR building was able to outperform a minimally code-complying 30\% WWR with the use of aggressively high-performing envelope selections. For example, in New York City within the High-Density context, a 75\% WWR building with the highest performance glass $\left(\mathrm{U}=1.70 \mathrm{~W} / \mathrm{m}^{2} \mathrm{~K}\left[0.30 \mathrm{Btu} / \mathrm{h} \mathrm{ft}{ }^{2} \mathrm{~F}\right], \mathrm{SHGC}=0.2\right)$ and best wall assembly $\left(\mathrm{U}=0.15 \mathrm{~W} / \mathrm{m}^{2} \mathrm{~K}\left[\mathrm{R}=37.8 \mathrm{ft}{ }^{2} \mathrm{~F} \mathrm{hr} / \mathrm{Btu}\right]\right)$ could outperform a $30 \% \mathrm{WWR}$ building with a minimally code compliant glass $\left(\mathrm{U}=2.84 \mathrm{~W} / \mathrm{m}^{2} \mathrm{~K}\left[0.50 \mathrm{Btu} / \mathrm{h} \mathrm{ft}{ }^{2} \mathrm{~F}\right], \mathrm{SHGC}=0.4\right)$ and wall assembly (Assembly $\mathrm{U}=0.365 \mathrm{~W} / \mathrm{m}^{2} \mathrm{~K}\left[\mathrm{R}=15.6 \mathrm{ft}{ }^{2} \mathrm{~F} \mathrm{hr} / \mathrm{Btu}\right]$ ), resulting in a $2 \%$ lower total heating/cooling/lighting energy use. ${ }^{9} \mathrm{It}$ is important to note that achieving this aggressive envelope performance may not be economically feasible in today's market.

As one might expect, the preferred glass selections showed that in the cool climates (Beijing and New York), lowering the U-value was always the more important glass characteristic, whereas in the warmer climate, lowering the SHGC was always paramount. However, reviewing the data revealed that when it comes to selecting the lower or higher SHGC in the cooler climates, the preferred choice may not be intuitively clear. The ASHRAE model energy code [33] specifies a maximum Solar Heat Gain Coefficient (SHGC); therefore, a designer may assume that a lower SHGC would result in energy savings, but that was not always the case, depending on WWR, Window Shading as well as other parameters.

\footnotetext{
${ }^{9}$ The other parameters remained the same between the two cases: rectangle, 0 degree orientation, no shading, lower plug-loads, and lower thermal mass.
} 
It is important to investigate not only the optimized solutions, but the nearly-optimized solutions. As shown in Figure 16, Building Rotation was a relatively important design parameter with regard to EUI, and, not surprisingly, a 0 degree rotation (long facades facing north and south) was generally preferable. However, designers facing other siting constraints may wonder about the energy penalty of a compromise. In New York, the second best rotation: (30degeres) resulted in a slight increase in EUI on average over the 0-degree rotation. The result was most pronounced with the rectangular shaped buildings with $75 \%$ WWR; yet even in these extreme cases the second-best rotation resulted in a $2 \%$ increase on average in EUI over the best orientation. In some cases Building Rotation had no effect on EUI, (e.g. in Shenzhen the T-shape building with 30\% WWR, High Performance glass, and a Window Shading projection factor of 50\%).

The selection of the optimal Building Shape for low EUI was dependent on other factors. In Beijing and New York, the rectangle-shaped buildings resulted in both the lowest and highest EUIs. As one might expect, the rectangular shape generally performed better than the others with proper Solar Orientation (i.e. the long facades facing due north and south or within 30 degrees thereof), and worse than the others with improper orientation (i.e. the long facades facing east and west, or within 30 degrees thereof).

Even with the proper orientation, however, the energy performances of the rectangular building cases, with their large surface areas, were highly impacted by the selection of envelope parameters. Examples include a building in New York with 0 degree orientation (long facades north and south) and 75\% WWR. With the highest performing glass (U=1.70 W/m2K $[0.30(\mathrm{Btu} / \mathrm{h} \mathrm{ft} 2 \mathrm{~F}])$ and wall assembly $(\mathrm{U}=0.15 \mathrm{~W} / \mathrm{m} 2 \mathrm{~K}[\mathrm{R}=37.8 \mathrm{ft} 2 \mathrm{~F} \mathrm{hr} / \mathrm{Btu}])$, the rectangular building's EUI outperformed the square building's by $4 \%$. However, if the envelope were downgraded to the next-best performing glass $(\mathrm{U}=2.84 \mathrm{~W} / \mathrm{m} 2 \mathrm{~K}$ $(0.50[\mathrm{Btu} / \mathrm{h} \mathrm{ft} 2 \mathrm{~F}])$ and wall assembly $(\mathrm{U}=0.22 \mathrm{~W} / \mathrm{m} 2 \mathrm{~K}[\mathrm{R}=25.8 \mathrm{ft} 2 \mathrm{~F} \mathrm{hr} / \mathrm{Btu}])$, the rectangular building's EUI would increase by $14 \%$. With the down-graded envelope parameters, the square shape would actually out-perform the rectangle by $4 \%$. In summary, the rectangular buildings were more susceptible to the detrimental effects of poor envelope design and "value engineering", a process common in building design in which design parameters are substituted with less expensive choices late in the design process.

In summary, Building Shape influenced the building's EUI. However, a well-designed envelope, especially one with a low WWR, was somewhat robust to the influence of Building Shape. Put another way, with poorer performing envelope properties, shape became an even more important design parameter. 


\section{DISCUSSION}

\subsection{Potential for Generalized Pre-Design Guidance}

The results here confirm the important impact of early architectural design decisions on building energy performance. When starting design on a low-energy project, it would be helpful for architects to have guidance, such as which design parameters can potentially make a large impact on energy performance in their climate/city/urban district. Yet, the use of energy simulation in early design stages is currently limited because teams lack either the budget or skills, and/or because feedback from energy modelers often cannot keep up with the highly iterative design explorations in early design phases. With parametric simulation, researchers can test a large enough solution space to provide a pre-simulated, pre-design resource (potentially for multiple architecture teams) that will give instant feedback at a low cost. The intent of this resource is to augment traditional energy modeling in design.

\subsection{Model Assumptions and Potential Shortcomings}

Users should be aware of potential difficulties in creating pre-simulated design guidelines. As discussed in Section 3.10, the parameter selection and range have a signification influence on the practicability of guidelines. Modelers face the challenge of striking a balance between limiting the numbers of variables to allow instant feedback without restricting the decision maker's choices.

Furthermore, the user must acknowledge the uncertainty of the simulation engine and, more importantly, the model inputs at this early stage of design. For example, as shown in Table A2, mathematically the Best Passive Winter Survivability case in Beijing included window shading (projection factor 0.25). The second-best design solution was identical except that it contained no window shading, and logically this design should have prevailed. Inspecting the data reveals that the temperature results were identical down to a fraction of a degree. In reality the simulation cannot distinguish between these two design cases, and the authors only included these results for the purpose of discussion.

Interpretation of energy modeling results always requires a fundamental understanding of the energy model engine, the modeling techniques used, and the assumptions made in the model, as illustrated by the examples below. First, as described in Section 3.10, the lack of differentiation between the thermal mass parameters may have partially resulted from an artifact of the simulation rather than a real-life phenomenon. Second, in this research, the ventilation rate was independent of WWR. One can imagine that in situations where window size affects passive cooling potential, the design optimizations might change. Third, here the model included daylight dimming controls. In buildings without these controls this assumption would overstate the energy-saving potential of daylight. 
Nevertheless, here an increase in WWR consistently resulted in an increase in EUI, as described in Section 3.12. Athalye et al 2013 [23] found the same trend in their research but noted that this result differed from earlier studies [45,46] that used higher lighting power densities.

\subsection{Comparison to Standard Practice}

The authors believe that the above concerns can be addressed through education and documentation to inform the end-user. The value of simulation-based early-design guidelines must be weighed against their alternative --namely avoiding or postponing the use of energy simulation.

Design teams that use energy simulation typically apply it later in the design-process, as mentioned in Section 1, simulating a handful of design options one at a time, by hand. The advantage of this later-stage simulation is that more of the design parameters are known. For example, having a correctly modeled HVAC system would allow for a more accurate comparison of the energy performance of various glass types. However, by postponing simulation until more design decisions have been made, design teams miss important opportunities to impact building performance. Therefore, the authors intend for this early-stage simulation method to augment, not replace, later simulation as the design evolves. A similar parametric approach could be repeated later in the design process, focusing on the design questions at hand, for example testing detailed energy conservation measures once general parameters such as building shape have been determined.

\section{CONCLUSION}

This research presented a framework for creating a parametric energy simulation-based resource for early-phase architectural design. The authors performed a case-study of a prototype multi-family residential building considering multiple energy-related objectives including passive survivability. They tested the impact of urban context on energy results and design optimization.

\section{ACKNOWLEDGMENTS}

The authors thank Arpan Bakshi and Jason Kirkpatrick for their consultation and gratefully acknowledge grants from the Harvard Graduate School of Design and the Joint Center for Housing Studies.

\section{REFERENCES}

[1] United Nations Human Settlements Programme. State of the World's Cities 2008/2009: Harmonious Cities. Ed. UNHABITAT. Routledge, 2008.

[2] American Institute of Architects. 2030 Commitment: Measuring Industry Progress Toward 2030, 2013.

[3] Samuelson, H.W., Lantz, A., \& Reinhart, C. F. Non-technical barriers to energy model sharing and reuse. Building and Environment, 54 (2012), 71-76. 
[4] Paulson, B. Designing to Reduce Construction Costs. Journal of the Construction Division, American Society of Civil Engineers, 102(CO4), (1976) 587-592.

[5] Hensen, J., \& Lamberts, R. (2011). Introduction in J. Hensen \& R. Lamberts (Eds.), Building Simulation for Practical Operational Optimization. London: Spon Press.

[6] Attia, S., Gratia, E., De Herde, A. and Hensen, J.L., Simulation-based decision support tool for early stages of zeroenergy building design. Energy and Buildings 49 (2012).

[7] American Institute of Architects. An Architect's Guide to Integrating Energy Modeling in the Design Process, 2012.

[8] Kotkin, J. \& Cox, W. The World's Fastest-Growing Megacities. Forbes.com.

http://www.forbes.com/sites/joelkotkin/2013/04/08/the-worlds-fastest-growing-megacities/

[9] Ochoa, C.E., \& Capeluto, I.G. Advice tool for early design stages of intelligent facades based on energy and visual comfort approach. Energy and Buildings, 41(5), 2009.

[10] Petersen, S., \& Svendsen, S. Method and simulation program informed decisions in the early stages of building design. Energy and buildings, 42(7), 2010.

[11] Christensen, C., Anderson, R., Horowitz, S., Courtney, A. and Spencer, J., BEopt software for building energy optimization: features and capabilities. National Renewable Energy Laboratory, 2006.

[12] Wang, W., Zmeureanu, R. and Rivard, H., Applying multi-objective genetic algorithms in green building design optimization. Building and environment, 40(11), 2005.

[13] Tuhus-Dubrow, D. and Krarti, M., Genetic-algorithm based approach to optimize building envelope design for residential buildings. Building and environment, 45(7), 2010.

[14] Morris, M.D., Factorial sampling plans for preliminary computational experiments. Technometrics, 33(2), 1991.

[15] Lomas, K.J. and Eppel, H., Sensitivity analysis techniques for building thermal simulation programs. Energy and buildings, 19(1), 1992.

[16] Lam, Joseph C., and Sam CM Hui. Sensitivity analysis of energy performance of office buildings. Building and Environment 31.1 (1996): 27-39.

[17] Heiselberg, P., Brohus, H., Hesselholt, A., Rasmussen, H., Seinre, E. and Thomas, S., Application of sensitivity analysis in design of sustainable buildings. Renewable Energy, 34(9), 2009.

[18] Samuelson, H., Ghorayshi, A., and Reinhart, C.. Analysis of a simplified calibration procedure for 18 design-phase building energy models. Journal of Building Performance Simulation (2014): 1-13.

[19] Strømann-Andersen, J., and Sattrup, P. The urban canyon and building energy use: Urban density versus daylight and passive solar gains. Energy and Buildings 43.8 (2011).

[20] Pisello, Anna Laura, John E. Taylor, Xiaoqi Xu, and Franco Cotana. "Inter-building effect: Simulating the impact of a network of buildings on the accuracy of building energy performance predictions." Building and Environment 58, 2012.

[21] Bueno, B., Norford, L., Pigeon, G., and Britter, R. A resistance-capacitance network model for the analysis of the interactions between the energy performance of buildings and the urban climate. Building and Environment, $54,2012$. 
[22] Gracik, S., Heidarinejad, M., Liu, J., \& Srebric, J. Effect of urban neighborhoods on the performance of building cooling systems. Building and Environment, 90, 2015.

[23] Athalye, R.A., Xie, Y., Liu, B, and Rosenberg, M.I., "Analysis of Daylighting Requirements within ASHRAE Standard 90.1." Pacific Northwest National Laboratory, 2013.

[24] Reinhart, C.F., \& Davila, C.C. Urban building energy modeling-A review of a nascent field. Building and Environment, 97, 2016.

[25] Thornton, B.A., Rosenberg, M.I., Richman, E.E., Wang, W., Xie, Y., Zhang, J., Cho, H., Mendon, V.V., Athalye, R.A., and Liu, B. , Achieving the 30\% Goal: Energy and Cost Savings Analysis of ASHRAE Standard 90.1-2010, Pacific Northwest National Laboratory -20405, 2011.[26] Selkowitz et al., The impact of fenestration on energy use and peak loads in daylighted commercial buildings, 1984.

[27] Li, D, J. C. Lam, and S. L. Wong. Daylighting and its effects on peak load determination. Energy 30.10 (2005): 1817 1831.

[28] Coley, D. and Kershaw, T., 2010. Changes in internal temperatures within the built environment as a response to a changing climate. Building and environment, 45(1), 2010.

[29] Urban Green Council. Building Resiliency Task Force Report: Baby It’s Cold Inside, (2014).

[30] Urban Green Council. Building Resiliency Task Force: Report to Mayor Michael R. Bloomberg \& Speaker Christine C. Quinn. (2013).

[31] Collins, K. J. "Low indoor temperatures and morbidity in the elderly." Age and Ageing 15.4 (1986): 212-220.

[32] Basu, Rupa, and Jonathan M. Samet. "Relation between elevated ambient temperature and mortality: a review of the epidemiologic evidence." Epidemiologic reviews 24.2 (2002): 190-202.

[33] ASHRAE/IESNA Standard Project Committee 90.1, ASHRAE 90.1-2010 Standard-Energy Standard for Buildings Except Low-Rise Residential Buildings, Appendix G. ASHRAE, Inc., 2010.

[34] US Department of Energy. Commercial Prototype Building Models. http://www.energycodes.gov/commercialprototype-building-models

[35] Crawley, Drury B., "Which Weather Data Should You Use for Energy Simulations of Commercial Buildings?" ASHRAE Transactions, 104(2), 1998.

[36] Crawley, D., Lawrie, L., "Rethinking the TMY: Is the 'Typical Meteorological Year Best for Building Performance Simulation?", Proceedings of Building Simulation, Hyderabad, India, 2015.

[37] Hacker, J., Capon, R., Mylona, A. "Use of climate change scenarios for building simulation: the CIBSE future weather years." The Chartered Institution of Building Services Engineers, London, UK. CIBSE TM48: 2009.

[38] EnergyPlus, Version 8.1 US Department of Energy. http://apps1.eere.energy.gov/buildings/energyplus/

[39] Crawley, D.B., Hand, J.W., Kummert, M. and Griffith, B.T. "Contrasting the capabilities of building energy performance simulation programs." Building and Environment 43(4), 2008.

[40] Ward, Gregory J. "The RADIANCE lighting simulation and rendering system." Proceedings of the 21st annual conference on Computer graphics and interactive techniques, 1994. 
[41] Grasshopper, Version 0.9.0076. http://www.grasshopper3d.com/

[42] Rhinoceros, Version 5. https://www.rhino3d.com/

[43] ArchSim., Version 1.4.0 http://archsim.com/

[44] Amazon Web Services (AWS), http://aws.amazon.com/

[45] Carmody, J. Window Systems for High Performance Buildings. W.W. Norton \& Company. New York, NY, 2004.

[46] Glass Association of North America. Window-to-Wall Ratio and Energy Performance. Presentation to ASHRAE Standard 90.1 Envelope Subcommittee. ASHRAE Winter Meeting, ASHRAE, Orlando, FL. 2010.

\section{APPENDIX A}

Table A1

\section{Other Model Assumptions}

Weather data, unless otherwise noted (passive survivability):

USA_NY_New.York-Central.Park_TMY3.epw, CHN_Guangdong.Shenzhen.594930_SWERA.epw, CHN_Beijing.Beijing.545110_IWEC.epw.

Floor \& Ceiling: Adiabatic (The simulated residence is bordered by other conditioned residences above and below.)

\section{Lights:}

1. Continuous Dimming

2. Power-Density: $6.5 \mathrm{~W} / \mathrm{m}^{2}\left(0.6 \mathrm{~W} / \mathrm{ft}^{2}\right)$ per ASHRAE 90.12010

3. Illuminance Target: 300 lux ( 28 footcandles)

Occupants Density: $18.6 \mathrm{~m}^{2} /$ person $\left(200 \mathrm{ft}^{2} /\right.$ person)

Conditioning:

1. Heating Set Point: $20^{\circ} \mathrm{C}\left(68^{\circ} \mathrm{F}\right)$

2. Cooling Setpoint: $26^{\circ} \mathrm{C}\left(79^{\circ} \mathrm{F}\right)$

5. Mechanical Ventilation: On

6. Min. Fresh Air per Person: $0.001 \mathrm{~m}^{3} / \mathrm{s}$-person (2.12 $\mathrm{ft}^{3} / \mathrm{min}$-person)

7. Min. Fresh Air per Area: $0.001 \mathrm{~m}^{3} / \mathrm{s}-\mathrm{m}^{2}\left(0.197 \mathrm{ft}^{3} / \mathrm{min}-\mathrm{ft}^{2}\right)$

8. Economizer: Yes

9. Heat Recovery: None

\section{Ventilation:}

1. Infiltration: 1 Air Change per Hour (ACH)

2. Scheduled Ventilation: 0.6 ACH

3. Natural Ventilation: No

5. Hybrid Ventilation: No

\section{Schedules:}

The following occupancy schedule was used seven days per week, based on the US DOE's Prototype Models [20] (Models are based on ASHRAE 90.1. 2004.) All other operating schedules were based on this schedule. The diversity factor for each hour from 1:00 to 24:00 is as follows:1,1,1,1,1,1,0.9,0.7,0.4,0.2,0.2,0.2, 


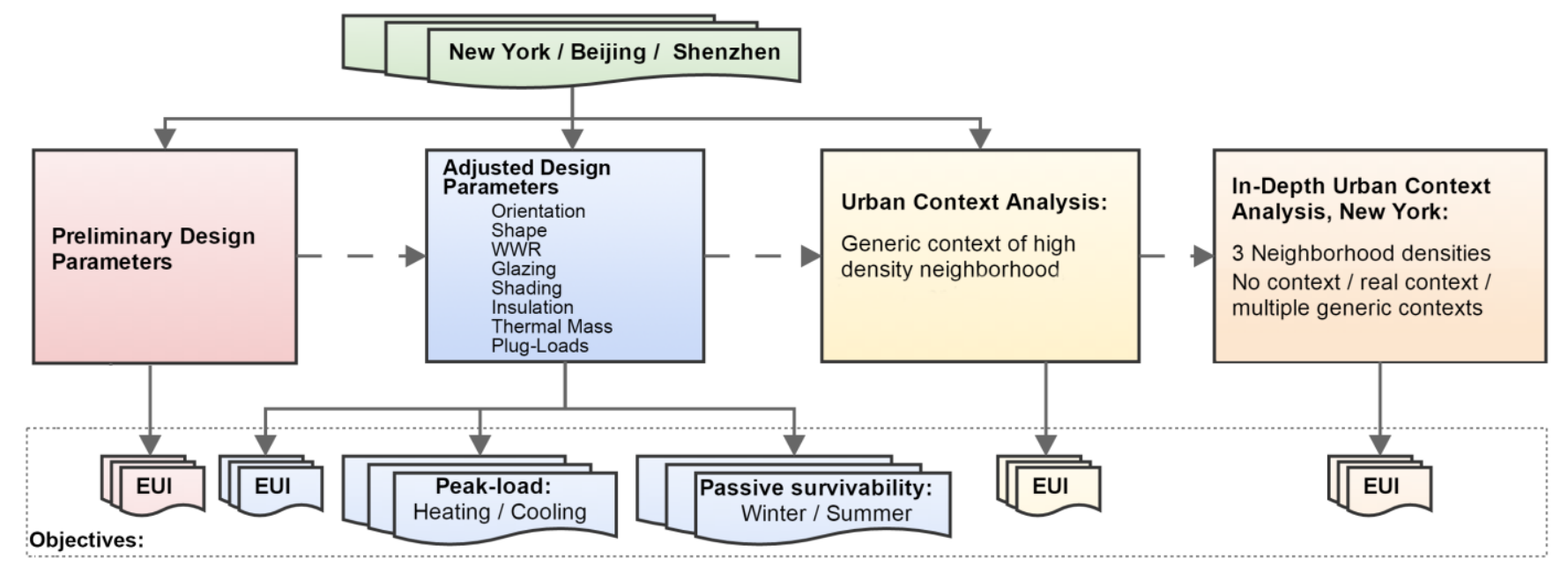

Figure A1: Overview of Parametric Simulation Research

Table A2: Best Design Parameters for Different Objectives

\begin{tabular}{|c|c|c|c|c|c|c|}
\hline $\begin{array}{c}\text { Case (all cases here are without context } \\
\text { unless otherwise noted) }\end{array}$ & Shape & $\begin{array}{c}\text { Solar } \\
\text { Orient } \\
\text { ation }\end{array}$ & WWR & Glass Type & $\begin{array}{l}\text { Shading } \\
\text { Projection } \\
\text { Factor }\end{array}$ & $\begin{array}{c}\text { Wall } \\
\text { Construction }\end{array}$ \\
\hline \multicolumn{7}{|c|}{ BEIJING } \\
\hline Lowest EUI (with context) & Rectangle & 180 & 0.3 & Lower SHGC \& Lower U & 0 & WallBest \\
\hline Lowest Peak Heating & Rectangle & 0 & 0.3 & Lower SHGC \& Lower U & 0 & WallBest \\
\hline Best Passive Survivability Winter & T-Shape & 150 & 0.3 & Lower SHGC \& Lower U & $0.25^{*}$ & WallBest \\
\hline Highest EUI & Rectangle & 90 & 0.75 & GlassASHRAE & 0 & WallASHRAE \\
\hline \multicolumn{7}{|c|}{ NEW YORK CITY } \\
\hline Lowest EUI & Rectangle & 180 & 0.3 & Lower SHGC \& Lower U & 0.5 & WallBest \\
\hline Lowest EUI (with context) & Rectangle & 90 & 0.3 & Lower SHGC \& Lower U & 0 & WallBest \\
\hline Lowest Peak Heating & Square & 180 & 0.3 & Lower SHGC \& Lower U & 0 & WallBest \\
\hline Best Passive Survivability Winter & T-Shape & 180 & 0.3 & Lower SHGC \& Lower U & $0.5^{*}$ & WallBest \\
\hline \multicolumn{7}{|c|}{ SHENZHEN } \\
\hline Lowest EUI and Lowest Peak Cooling & T-Shape & 0 & 0.3 & Lower SHGC \& Lower U & 0.5 & WallBest \\
\hline Lowest EUI (with context) & Square & 30 & 0.3 & Lower SHGC Glass & 0 & WallBest \\
\hline Best Passive Survivability Summer & Rectangle & 150 & 0.3 & Lower SHGC Glass & 0.5 & WallBest \\
\hline Highest EUI & Rectangle & 90 & 0.75 & GlassASHRAE & 0 & WallASHRAE \\
\hline
\end{tabular}

Red $=$ objectives prioritizing maintaining heat

*discussed in Section 4.2 